\title{
Behaviour of untreated proliferative sickle retinopathy
}

\author{
P. I. CONDON AND G. R. SERJEANT \\ From the Medical Research Council Laboratories, University of the West Indies, \\ Kingston, Jamaica
}

SUMmaRY The development of ocular lesions in 313 patients with sickle cell disease followed up for periods of 1-8 years is described. Proliferative sickle retinopathy (PSR) was present on initial examination in $68(12 \%)$ of 567 eyes and developed in a further $46(8 \%)$ eyes during the study period. Spontaneous regression (autoinfarction) was present on initial examination in $33(49 \%)$ eyes with PSR initially and developed in a further $45(39 \%)$ eyes during the study. Development of PSR was more common in sickle cell-haemoglobin C (SC) disease, and autoinfarction appeared to occur more commonly in homozygous sickle cell (SS) disease. The two processes were delicately balanced, and some PSR lesions lasted less than a year before undergoing autoinfarction. Although the high prevalence of autoinfarction diminishes the clinical sequelae of PSR, blindness related to PSR occurred in 14/119 (12\%) eyes. Autoinfarction closes the feeding vessels of PSR lesions more elegantly than, and without the complications associated with, photocoagulation. A greater understanding of factors involved in the progression and regression of PSR is relevant to defining the role of photocoagulation in this condition.

Vascular occlusion in the peripheral retina in sickle cell disease results in peripheral arteriolar obstruction with the development of arterio-venous fistulae and proliferative retinopathy. ${ }^{12}$ This sequence has been confirmed by angiography in longitudinal studies $^{3}$ and occurs most frequently in sickle cellhaemoglobin C (SC) disease. ${ }^{4}$

Although proliferative sickle retinopathy (PSR) is common and may progress rapidly in some patients with SC disease, severe visual dysfunction is relatively uncommon. ${ }^{2}$ This anomaly may be reconciled, in part, by the tendency of PSR lesions to undergo autoinfarction, ${ }^{4-6}$ thus effectively curing the pathological circulation. Although representing progression in pathological terms, since further vaso-occlusion has occurred, autoinfarction reflects clinical improvement, as haemorrhage and possibly retinal detachment are rendered less likely. Autoinfarction occludes the lesions of PSR more elegantly than photocoagulation, and knowledge of this complication is relevant both to defining the role of photocoagulation and to understanding the natural history of sickle cell retinopathy. The

Correspondence to $\mathrm{Dr}$ G. R. Serjeant, Medical Research Council Laboratories, University of the West Indies, Mona. Kingston 7, Jamaica. balance between progression and regression (autoinfarction) also determines the clinical outcome of sickle cell eye disease. We present here, longitudinal observations on groups of patients with sickle cell syndromes followed up for periods up to 8 years.

\section{Material and methods}

Many patients from the Sickle Cell Clinic at the University Hospital of the West Indies have had ophthalmological examinations during the period 1970-78. Longitudinal observations, implying a minimum of 2 examinations at yearly intervals, were available in 313 patients (Table 1). A trial of light coagulation in PSR was conducted between 1973 and 1978 by treating the worst affected eye in 54 of these patients. Five blind eyes prohibiting retinal examination were also excluded from the description of retinal findings. This report describes the behaviour of retinal vessel disease in control eyes of the treatment series and in both eyes of patients not admitted to the treatment series excluding the 5 blind eyes detailed above (567 eyes in 313 patients).

The diagnosis of homozygous sickle cell (SS) disease, sickle cell-haemoglobin C (SC) disease, sickle cell- $\beta^{+}$thalassaemia $\left(\mathbf{S}^{+}+\right.$thal), and sickle cell- $\beta^{\circ}$ thalassaemia $\left(\mathbf{S} \beta^{\circ}\right.$ thal), were based on criteria 
Table 1 Summary of repeated ophthalmological examinations performed at approximately yearly intervals at sickle cell clinic

\begin{tabular}{|c|c|c|c|c|c|c|c|c|c|c|}
\hline \multirow{2}{*}{ Genotype } & \multirow{2}{*}{$\begin{array}{l}\text { Total } \\
\text { patients }\end{array}$} & \multicolumn{8}{|c|}{ Number of ophthalmological examinations } & \multirow{2}{*}{$\begin{array}{l}\text { Patient/years } \\
\text { of observation }\end{array}$} \\
\hline & & 2 & 3 & 4 & 5 & 6 & 7 & 8 & Total & \\
\hline SS & 115 & 76 & 21 & 13 & 2 & 2 & 1 & - & 296 & 460 \\
\hline SC & 157 & 58 & 32 & 22 & 20 & 16 & 6 & 3 & 562 & 669 \\
\hline $\mathbf{S} \beta+$ thal & 25 & 19 & 2 & - & - & 2 & 2 & - & 70 & 82 \\
\hline$S \beta^{\circ}$ thal & 14 & 8 & 4 & - & 1 & 1 & - & 一 & 39 & 58 \\
\hline SO Arab & 1 & - & 1 & - & - & - & - & - & 3 & 5 \\
\hline SD Punjab & 1 & 1 & - & - & - & - & 一 & - & 2 & 3 \\
\hline Total & 313 & 324 & 180 & 140 & 115 & 126 & 63 & 24 & 972 & 1277 \\
\hline
\end{tabular}

described elsewhere. ${ }^{7}$ Patients with sickle cellhaemoglobin O Arab (SO Arab) disease and sickle cell-haemoglobin D Punjab (SD Punjab) disease were identified by haemoglobin structural studies.

Ophthalmological examination included visual acuity, direct and indirect ophthalmoscopy through dilated pupils, retinal drawings in all patients, and retinal photography and fluorescein angiography where indicated. The extent of proliferative sickle retinopathy was recorded as the number of lesions and also the degree of circumferential and meridional involvement.

\section{Results}

Proliferative sickle retinopathy, defined either by leakage of intravenously administered fluorescein or by occluded fibrotic lesions, was present on initial examination in 68 eyes of 56 patients (14 SS; $37 \mathrm{SC} ; 4 \mathrm{~S} \beta^{+}$thal; $1 \mathrm{SO}$ Arab disease) and developed de novo during the period of observation in a further 46 eyes of 41 patients (10 SS; $28 \mathrm{SC} ; 1$ $\mathrm{S} \beta^{+}$thal; $2 \mathrm{~S} \beta^{\circ}$ thal). The prevalence of PSR at initial examination and arising de novo during the study is expressed as a proportion of the total number of patients in the longitudinal study in Table 2.

Progression, denoted by an increase in the number or size of existing PSR lesions (20 eyes) or development of PSR lesions de novo (46 eyes) occurred in 66 eyes of 59 patients (12 SS; $43 \mathrm{SC} ; 2 \mathrm{~S} \beta^{+}$thal; $2 \mathrm{~S} \beta^{\circ}$ thal) during the observation period. The mean age of patients showing progression in the 4 genotypes was $32 \cdot 4,27 \cdot 7,29 \cdot 0$, and $29 \cdot 0$ years respectively, with a median age in SC disease of 24 years. Rate of progression varied markedly, one patient developing 11 new PSR lesions in 18 months whereas another had gradual development or enlargement of a single lesion over 6-8 years.

There was a tendency for the most rapid progres-

Table 2 Prevalence of proliferative sickle retinopathy on admission to, and occurring de novo during, the longitudinal study

\begin{tabular}{|c|c|c|c|c|c|c|c|c|}
\hline \multirow{3}{*}{ Genotype } & \multirow{2}{*}{\multicolumn{2}{|c|}{ Total examined }} & \multicolumn{6}{|c|}{ Proliferative sickle retinopathy } \\
\hline & & & \multicolumn{2}{|c|}{ On initial examination } & \multicolumn{2}{|c|}{ Arising de novo during study } & \multicolumn{2}{|c|}{ At end of study } \\
\hline & Patients & Eyes* & Patients & Eyes & Patients & Eyes & Patients & Eyes \\
\hline SS & 115 & 221 & $14(12 \%)$ & $16(7 \%)$ & $10(9 \%)$ & $13(6 \%)$ & $23(20 \%)$ & $29(13 \%)$ \\
\hline SC & 157 & 270 & $37(24 \%)$ & $45(17 \%)$ & $28(18 \%)$ & $30(11 \%)$ & $63(40 \%)$ & $75(28 \%)$ \\
\hline $\mathbf{S} \beta+$ thal & 25 & 46 & $4(16 \%)$ & $5(11 \%)$ & 1 & 1 & $5(20 \%)$ & $6(13 \%)$ \\
\hline $\mathbf{S} \beta^{\circ}$ thal & 14 & 26 & 0 & 0 & 2 & 2 & 2 & 2 \\
\hline SO Arab & 1 & 2 & 1 & 2 & 0 & 0 & 1 & 2 \\
\hline SD Punjab & 1 & 2 & $\mathbf{0}$ & 0 & 0 & 0 & 0 & $\mathbf{0}$ \\
\hline Total & 313 & 567 & $56(18 \%)$ & $68(12 \%)$ & $41(13 \%)$ & $46(8 \%)$ & $94(30 \%)$ & $114(20 \%)$ \\
\hline
\end{tabular}

*Excluding 54 eyes included in trial of light coagulation (8 SS; $40 \mathrm{SC} ; 4 \mathrm{~S} \beta^{+}$thal; $2 \mathrm{~S} \beta^{\circ}$ thal) and 5 blind eyes (1 SS; 4 SC) not allowing retinal examination. 


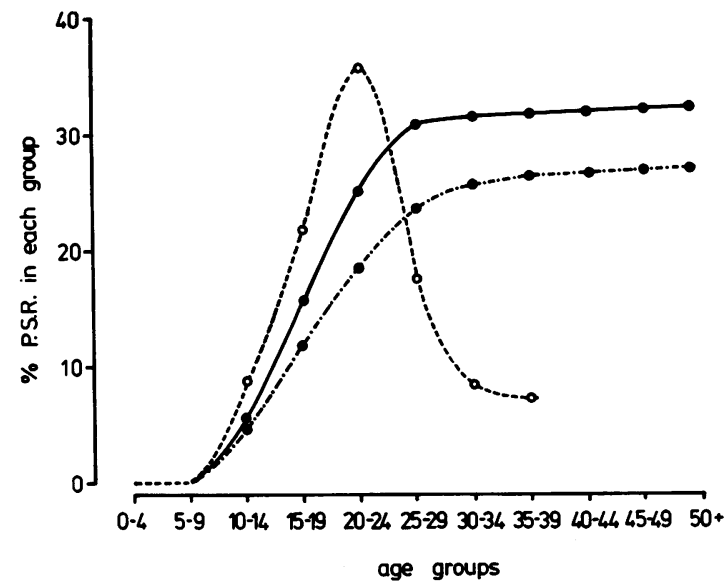

Fig. 1 Prevalence of PSR according to age in different groups of patients with $S C$ disease.

O- - - $\bigcirc$ PSR developing de novo.

○- - - - 0 Cumulative prevalence of PSR in

longitudinal study. Cumulative prevalence of PSR in cases showing progression.

sion to be apparent in young patients. In the 12 patients with SS disease showing progression 19 new lesions occurred in 4 patients under the age of 25 years (mean 4.8 lesions/patient) compared to 15 new lesions in 8 patients over this age (mean 1.9 lesions/patient). Similarly, in 43 patients with SC disease, 58 new lesions developed in 18 patients under the age of 25 years (mean 3.2 lesions/patient) compared to 53 in 25 patients over this age (mean $2 \cdot 1$ lesions/patient). Analysis of the age distribution of patients with SC disease developing PSR for the first time indicated that the highest risk period, accounting for $36 \%$ of cases, was $20-24$ years (Fig. 1). Two-thirds of patients developing PSR de novo were in the 15-29 age group, which included only $46 \%$ of the total patient group. Young patients also showed the most florid progression of PSR lesions, as illustrated in Fig. 2.

Regression, denoted by avascular PSR lesions, was apparent on initial examination in 33 eyes of 26 patients (10 SS; $13 \mathrm{SC} ; 2 \mathrm{~S} \beta^{+}$thal; 1 SO Arab disease) and cessation of perfusion of individual PSR lesions was observed during the study period in 45 eyes of 39 patients (11 SS; $24 \mathrm{SC}$; $2 \mathrm{~S} \beta+$ thal; $2 S \beta^{\circ}$ thal), 9 eyes of which also had avascular lesions on initial examination. Of the 114 eyes with PSR $31(27 \%)$ showed complete autoinfarction and $38(33 \%)$ partial autoinfarction by the end of the study period. Complete autoinfarction was commoner in eyes showing no increase in PSR during the study period (19 eyes), but also occurred in eyes showing an increase in PSR (2 eyes) and in those developing PSR de novo (10 eyes). Partial autoinfarction occurred in 16,12 , and 10 eyes of the 3 groups respectively. The prevalence of autoinfarction of PSR lesions in eyes of the different genotypes is summarised in Table 3 . The average age of patients observed to be undergoing auto-

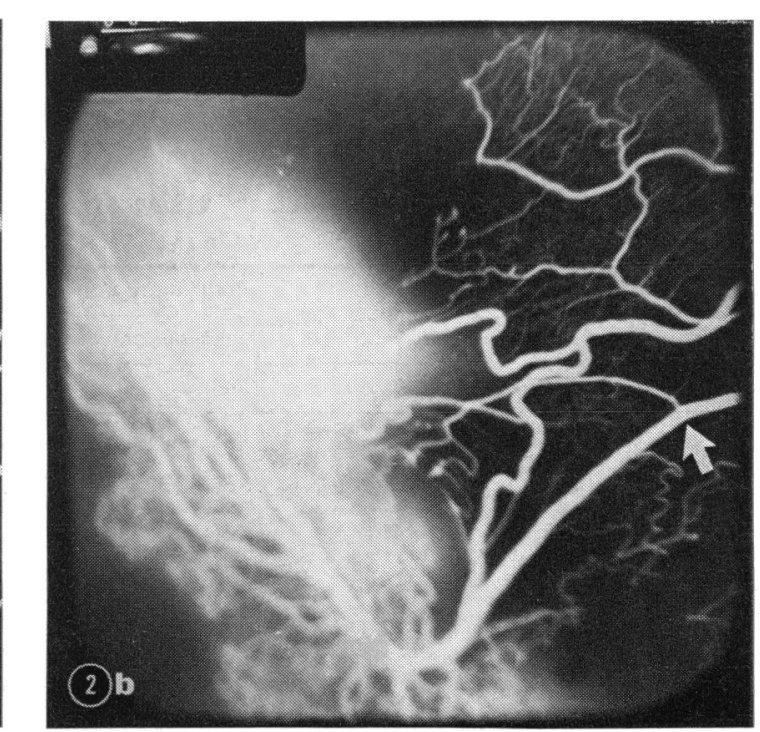

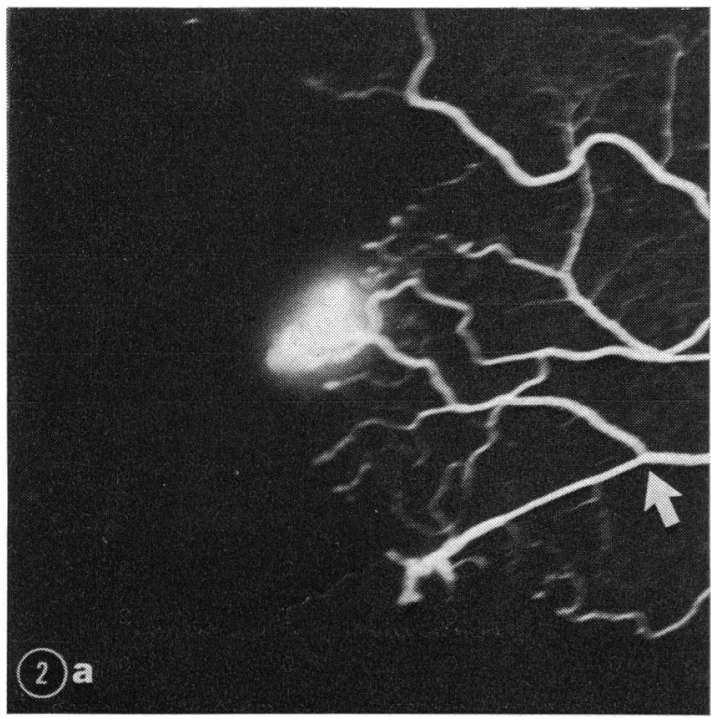

Fig. 2 17-year-old female with SC disease demonstrating rapid progression from (a) to (b) 16 months later. Dynamic developments have changed the relative calibres of vessels. Arrows indicate the same vessel bifurcation. 
Table 3 Prevalence of autoinfarction of proliferative sickle retinopathy on admission to, and occurring during, the longitudinal study

\begin{tabular}{|c|c|c|c|c|c|c|c|c|}
\hline \multirow{3}{*}{ Genotype } & \multirow{2}{*}{\multicolumn{2}{|c|}{ Totals affected by PSR }} & \multicolumn{6}{|c|}{ Autoinfarction } \\
\hline & & & \multicolumn{2}{|c|}{ On initial* examination } & \multicolumn{2}{|c|}{ Arising during study } & \multicolumn{2}{|c|}{ At end of study $\dagger$} \\
\hline & Patients & Eyes & Patients & Eyes & Patients & Eyes & Patients & Eyes \\
\hline SS & 23 & 29 & $10(71 \%)$ & $10(63 \%)$ & $11(48 \%)$ & $13(45 \%)$ & $17(74 \%)$ & $19(66 \%)$ \\
\hline SC & 63 & 75 & $13(35 \%)$ & $18(40 \%)$ & $24(38 \%)$ & $28(37 \%)$ & $32(51 \%)$ & $41(55 \%)$ \\
\hline $\mathbf{S} \beta+$ thal & 5 & 6 & 2 & 3 & 2 & 2 & 4 & 5 \\
\hline $\mathbf{S} \beta^{\circ}$ thal & 2 & 2 & $\mathbf{0}$ & 0 & 2 & 2 & 2 & 2 \\
\hline SO Arab & 1 & 2 & 1 & 2 & 0 & $\mathbf{0}$ & 1 & 2 \\
\hline Total & 94 & 114 & $26(46 \%)$ & $33(49 \%)$ & $39(41 \%)$ & $45(39 \%)$ & $56(60 \%)$ & $69(61 \%)$ \\
\hline
\end{tabular}

*Percentages expressed as proportion of those with PSR on initial examination. †Totals may not add up because some patients fall in both categories.

infarction was 32.2 years (SS), 29.6 years (SC), 29.0 years $\left(S \beta^{+}\right.$thal), and 33.0 years $\left(S \beta^{\circ}\right.$ thal $)$. The average age of patients attaining complete autoinfarction was 39.2 years (SS) and 35.2 years (SC).

A variety of mechanisms contributed to autoinfarction, of which the commonest was occlusion of the arteriolar feeding vessels as part of a centripetal arteriolar retraction (Fig. 3). This process might occur even in extensive circumferential involvement by PSR (Fig. 4) and was occasionally associated with simultaneous progression in the
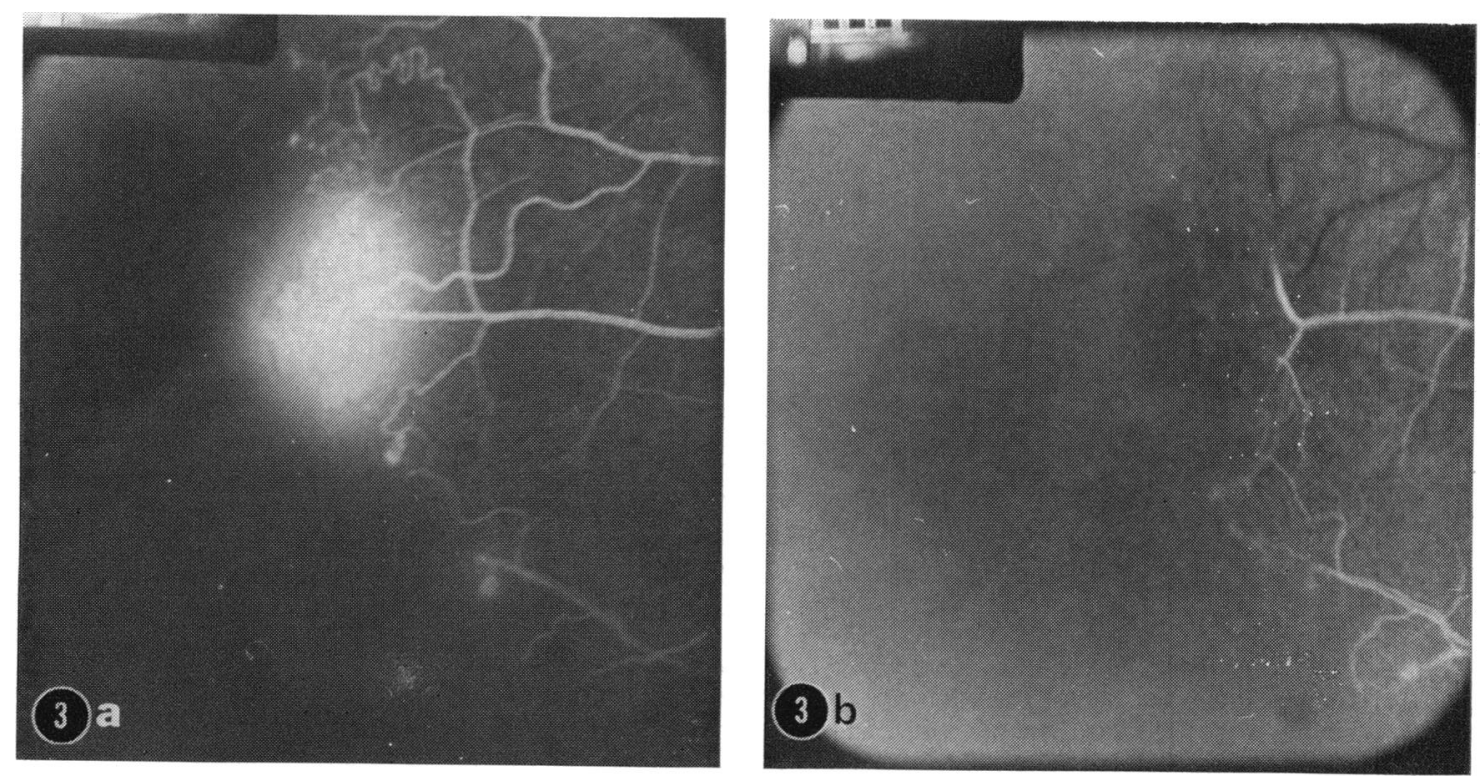

Fig. 3 21-year-old male patient with SS disease. Fluorescein angiogram of right temporal periphery indicates leaking lesion (a) with subsequent disappearance 2 years later (b).

same eye. Avulsion of an optic disc PSR occurred in 1 patient with SC disease (Fig. 5), resulting in a massive vitreous haemorrhage which subsequently cleared to $6 / 12$ visual acuity. In 2 patients haemorrhage into the PSR lesion appeared to precipitate regression of the lesion, and in 2 other patients vitreous traction of PSR lesions probably compromised flow in the feeding arterioles.

The balance of the processes of progression and regression in the current study are summarised in Fig. 6. Examples of the pattern of progression and 

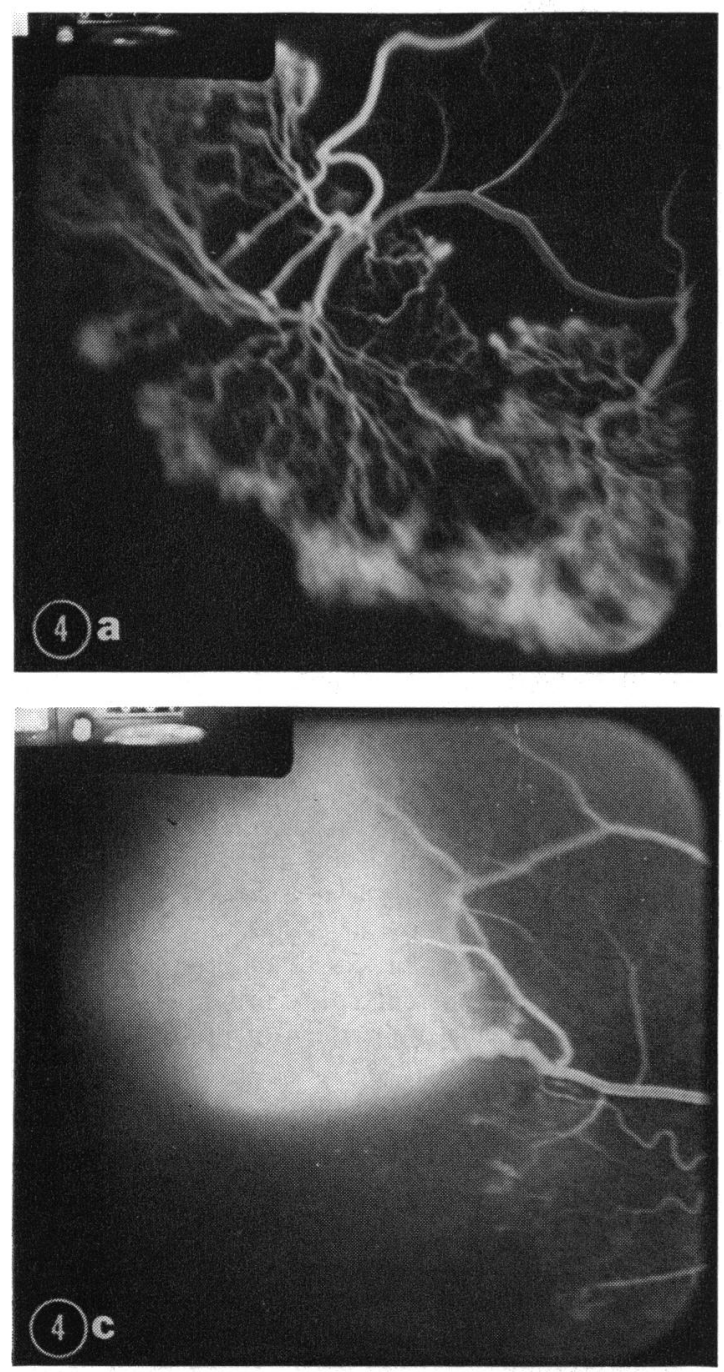

regression in individual patients are illustrated in Fig. 7. Individual PSR lesions were observed to develop and undergo autoinfarction during the study period in 19 eyes, lesions lasting less than 2 years in 10 eyes and less than 7 months in 3 eyes.

Proliferative sickle retinopathy showed no change in $10 / 29(34 \%)$ eyes in SS disease, $19 / 75(25 \%)$ in SC, $4 / 6(67 \%) \mathrm{S} \beta+$ thal, and $2 / 2$ (SO Arab disease) over periods of $71,40,17$, and 10 eye/years of observation respectively. Stability tended to be a feature of older patients, mean ages being $47,44,53$, and 46 years in the 4 genotypes respectively.

A history of, or signs compatible with, vitreous haemorrhage was present in 20 eyes of 17 patients (5 SS; $11 \mathrm{SC} ; 1 \mathrm{~S}^{+}$thal), and occurred during the study period in 9 eyes. Retinal haemorrhage without

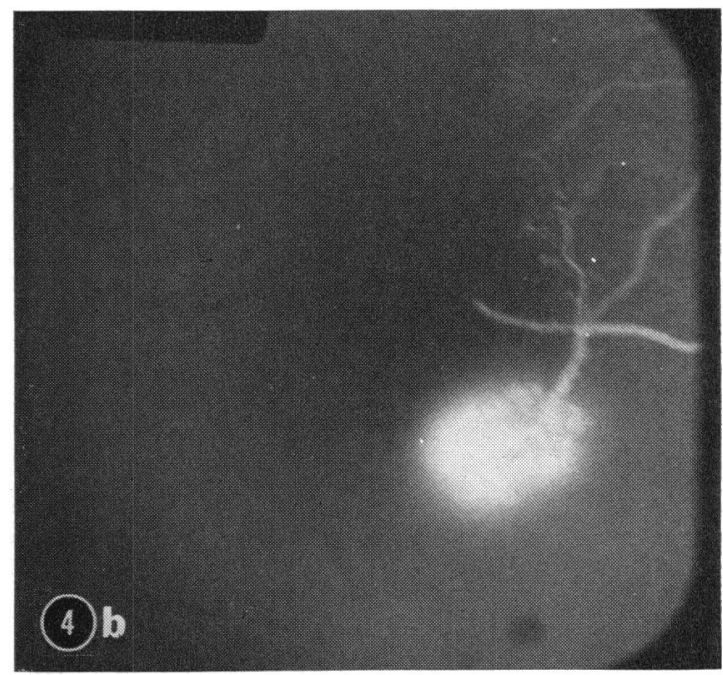

Fig. 4 24-year-old male patient with SC disease. Fluorescein angiogram of right inferotemporal periphery indicates extensively leaking lesion (a), with almost complete autoinfarction 2 years later (b), and simultaneous progression of an existing PSR lesion in the right superotemporal periphery (c).

vitreous involvement occurred in 5 eyes affected by PSR and in an additional 3 eyes without PSR but in which PSR subsequently developed. Vitreous haemorrhage was followed by autoinfarction of PSR lesions in 15/20 eyes affected, all lesions in the affected eye being occluded in 6 of these.

A visual acuity of $<6 / 60$ on admission to the study was probably attributable to PSR in 12 eyes of 11 patients ( $3 \mathrm{SS} ; 7 \mathrm{SC}$; $1 \mathrm{SO}$ Arab). In 5 of these eyes retinal examination was impossible, but a history of traction retinal detachment and previous surgery suggested a diagnosis of proliferative retinopathy. In 2 eyes acuity improved with the resolution of a vitreous haemorrhage, and acuity deteriorated to $<6 / 60$ during the study in a further 4 eyes of 4 patients. Acuity of $<6 / 60$ at the end of 

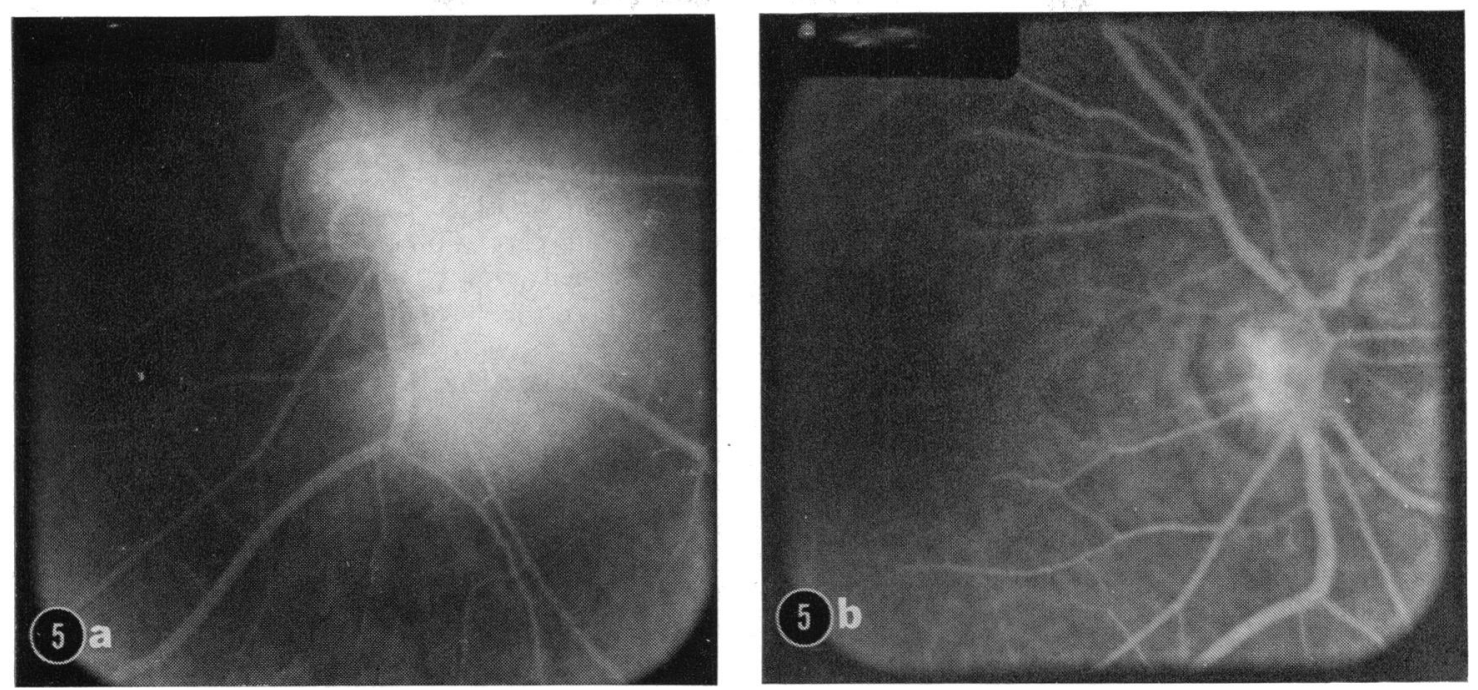

Fig. 5 33-year-old male patient with SC disease. Fluorescein angiogram of right optic disc indicates leaking PSR lesion (a) which subsequently avulsed 18 months later (b).

the study was attributed to PSR in 14 eyes, giving an overall prevalence of PSR related blindness in $14 / 119$ or $12 \%$. The age at blindness from presumed PSR related disease varied from 22 to 58 years, with half occurring between 22 and 28 years.

\section{Discussion}

Ocular examinations were initially performed on random patients unselected on the basis of ocular pathology, but repeated examination and hence

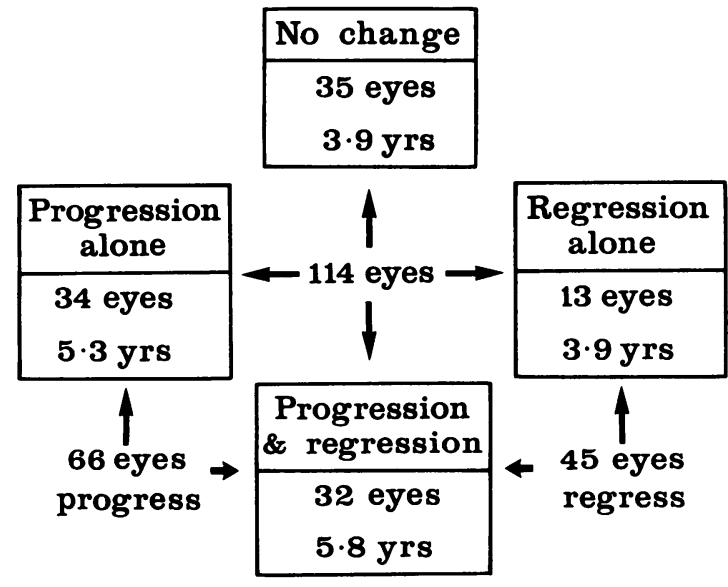

Fig. 6 Summary of the change observed during the study period in the 114 eyes affected by PSR. Mean duration of follow-up in each group indicated by lower figure in each box. inclusion in the longitudinal study was more likely in patients showing proliferative retinopathy. This ocular selection and the exclusion of 54 eyes with PSR entered in a separate photocoagulation study implies that the figures for prevalence of PSR on admission must be treated with caution. However, the progression of PSR, its development de novo, and its autoinfarction may be validly observed in this patient group.

The recording of serial changes provides problems, and no system is entirely satisfactory. Clinical parameters such as changes in visual acuity are too gross and insensitive as an index of progression. Retinal disease may be defined in terms of circumferential as well as meridional involvement from the ora serrata backwards, but this is also gross and difficult to document. Counting the number of PSR lesions may ignore the size of the lesion, a minute leaking lesion subtending $1-2^{\circ}$ of the retinal circumference or continuous PSR occupying $360^{\circ}$ of the circumference both being regarded as 1 lesion. This anomaly may be reduced in continuous circumferential involvement by referring to each $30^{\circ} \mathrm{seg}$ ment of PSR as a single 'lesion', and so $360^{\circ}$ involvement would constitute 12 'lesions'. Coalescence of multiple lesions may reduce the total number yet represent progression, whereas autoinfarction of a single lesion may leave 2 perfused areas, thereby increasing the number of 'lesions' yet representing regression. Despite these shortcomings the ability to record PSR in a numerical and analysable form does have advantages.

Factors contributing to the development of PSR 

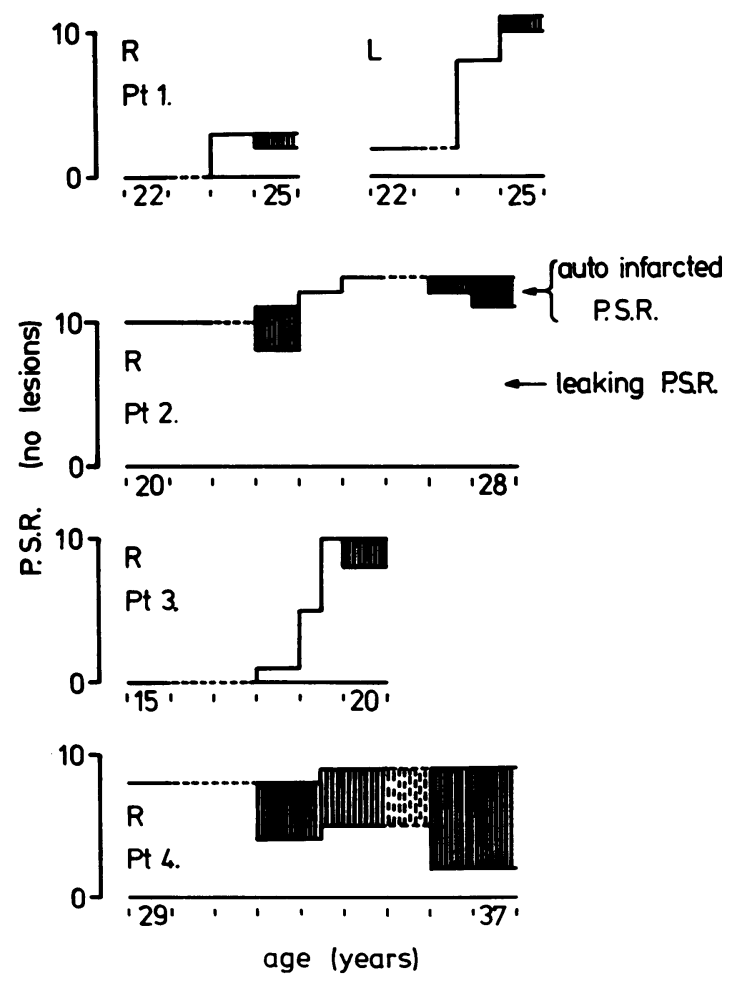

Fig. 7 Occurrence of leaking and auto-infarcted P.S.R. lesions in 5 eyes of 4 patient with SC disease. Dotted line represents the period before an episode for which ocular examinations were not available and during which the subsequent episode may have occurred.

are beginning to be understood. ${ }^{8}$ The high prevalence in the $S C$ and $S \beta^{+}$thal genotypes suggests the role of a high haematocrit, and there is a highly significant relationship with total haemoglobin, the prevalence of PSR rising steeply with haemoglobin levels above $12 \mathrm{~g} / \mathrm{dl}$. Whole blood viscosity rises in proportion to the square of the haematocrit, and the effect of high haemoglobin levels is probably explained by the increased viscosity and impairment of blood flow in small vessels. There is also a positive relationship between PSR and mean cell volume, suggesting that the MCV or a related haematological index may also influence peripheral blood flow. PSR also increases with age, which might be expected, since age reflects the duration of the vaso-occlusive process, and the effects of vasoocclusion are cumulative. However, the present study has identified an additional effect of age in the particularly rapid progression of PSR in the 15-29 year age group. Further analysis of haematological data is required to determine whether this effect is mediated through haematological changes at this age or is independent of them.

It was the apparent conflict between the rapidly progressive vascular disease observed in some young adults and the relative infrequency of severe visual dysfunction in older patients that suggested that spontaneous regression of lesions may be common. ${ }^{2}$ This has been amply confirmed by the present report, which indicates evidence of autoinfarction in 69/114 $(61 \%)$ of eyes with PSR by the end of the study period. The peak incidence of observed autoinfarction followed approximately 2 years behind the peak incidence of PSR lesions de novo, and average ages of patients demonstrating progression and regression were 32.4 and 32.2 years in SS and 27.7 and 29.6 years in SC disease respectively. The close temporal relationship observed between the development of PSR and its autoinfarction in many patients explains to some extent the relative infrequency of severe visual dysfunction. Autoinfarction renders PSR lesions less likely to haemorrhage and hence less likely to cause visual impairment.

The commonest cause of autoinfarction is probably progressive centripetal retraction of retinal vascular arcades, ${ }^{6}$ but a close relationship of autoinfarction and vitreous haemorrhage was noted in 15 eyes in the present study. Three-quarters of patients developing vitreous haemorrhages were subsequently found to have autoinfarcted PSR lesions. Whether spontaneous occlusion of feeder vessels precipitated haemorrhage from necrotic PSR lesions or whether primary haemorrhage resulted in vaso-occlusion is at present unclear.

Autoinfarction reduces the likelihood of complications from proliferative retinopathy, but severe visual impairment may still occur. Central visual loss related to PSR occurred during the study period in 4/114 eyes with PSR and was present in 14/119 $(12 \%)$ eyes at the end of the study. Although selflimiting to some extent, therefore, PSR still represents a highly significant cause of visual loss in sickle cell disease.

The ability of PSR lesions to undergo autoinfarction raises questions on the role of photocoagulation in this condition. This procedure is usually capable of closing feeder vessels and rendering lesions avascular but is not without risk, and may cause serious complications such as choriovitreal neovascularisation. Spontaneous autoinfarction achieves the same results more elegantly and without risk of many of the complications. However, cases prone to autoinfarction may still develop clinical visual impairment before this occurs. Before the role of photocoagulation in this condition can be defined, a greater understanding of the natural history of sickle cell eye disease, especially the 
mechanisms and factors contributing to autoinfarction, is necessary.

\section{References}

${ }^{1}$ Goldberg MF. Natural history of untreated proliferative sickle retinopathy. Arch Ophthalmol 1971; 85: 428-37.

${ }^{2}$ Condon PI, Serjeant GR. The progression of sickle cell eye disease in Jamaica. Doc Ophthalmol 1975; 39: 203-10.

${ }^{3}$ Raichand M, Goldberg MF, Nagpal KC, Goldbaum MH, Asdourian GK. Evolution of neovascularisation in sickle cell retinopathy. Arch Ophthalmol 1977; 95: 1543-52.

${ }^{4}$ Condon PI, Serjeant GR. Ocular findings in hemoglobin
SC disease in Jamaica. Am J Ophthalmol 1972; 74: 92131 .

${ }^{5}$ Okun E. Development of sickle cell retinopathy. Doc Ophthalmol 1969; 26: 574-81.

'Nagpal KC, Patrianakos D, Asdourian GK, Goldberg MF, Rabb M, Jampol L. Spontaneous regression (autoinfarction) of proliferative sickle retinopathy. Am J Ophthalmol 1975; 80: $885-92$.

${ }^{7}$ Serjeant GR. The Clinical Features of Sickle Cell Disease. Amsterdam: North Holland Publishing Company, 1974.

${ }^{8}$ Serjeant GR, Condon PI. Proliferative sickle retinopathya viscosity problem? Proceedings of the Xth World Conference of the European Society for Microcirculation. Basel: Karger, 1979; in press. 